\title{
sciendo
}

\section{MODEL OF PROCESSES OF THE AL25/30 MARINE ENGINE AND ITS VERIFICATION}

DOI 10.2478/ntpe-2018-0035

\author{
MSc. Dominika Cuper-Przybylska \\ Gdynia Maritime University POLAND
}

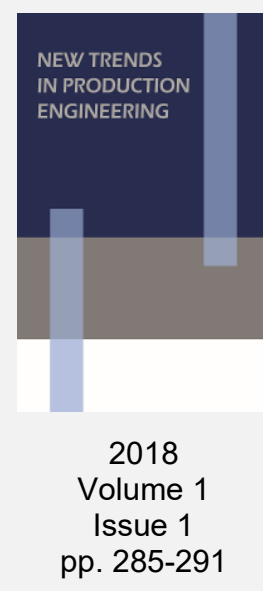

\begin{abstract}
The work presents a model of the marine diesel engine working process. The research object was the AL25/30 engine. The model consists of partial models of the combustion process in the engine cylinders, the heat exchange process, flows through air and exhaust channels, heat exchange in the intercooler and friction in mechanical components of the engine. The model includes a description of the processes taking place in the turbocharger also. The input data to the model and the verification data were the results of direct measurements on the research facility. The verification showed errors in the calculation of air and exhaust gas parameters not exceeding $11 \%$. The paper also presents an analysis of the results of fast-changing parameters, including combustion pressure in engine cylinders and pressures in individual gas channels. The designed model allows the analysis of the research facility operation and enables its further development towards the assessment of toxic compounds emission to the atmosphere.
\end{abstract}

Keywords: model engine, diesel, marine engine, combution

\section{INTRODUCTION}

Ship diesel internal combustion engines belong to a large group of thermal engines and are widely used in sea transport. They are used for the main propulsion of sea cargo ships and are used to power generators in a ship's power plant.

Conducting research on real objects in laboratories does not give a solution to the internal processes of the engine. Such tests generate high costs and are time-consuming, especially for marine engines. Creating mathematical models allows to limit financial resources as well as accelerate work on the development of piston constructions of marine engines. Computer simulations enable the creation of complex physical models in which one can describe, among others, the working process of a marine diesel engine.

In the process of creating engine management systems, there is a need for good validation capabilities. The generalized motor model is an asset and an indispensable tool in the hands of researchers, allowing to prove theoretical analysis. During the development of compression ignition engines, models are useful for testing and general engine testing (Cuper-Przybylska, 2016).

\section{MODELLING WORK PROCESSES PISTON ENGINE}

The combustion process consists of a number of partial processes such as fuel injection into the cylinder, spraying and spreading of fuel drops in the cylinder, evaporation and mixing with air, self-ignition, flame propagation in the cylinder along with turbulent mass movement and heat exchange with the engine cylinder construction elements, and piston movement caused by forces created. All of these phenomena occur simultaneously with varying intensity in different areas of the engine cylinder. It should also be noted that the combustion process takes place in a very short time, in the order of $1-10 \mathrm{~ms}$, with the simultaneous change in the volume of the cylinder space, resulting from the movement of the piston, change in pressure and temperature. Therefore, the calculations of the parameters of these phenomena are 
always reduced to significant simplifications in the description of phenomena, the applied mathematical apparatus and methods for solving equations. These limitations also result from the imperfections of measuring devices (Cuper-Przybylska, 2018).

It should be noted that the mathematical model of physical phenomena always requires the use of input data, which is usually recorded during measurements on real objects. For this reason, the scope of the applied limitations and simplifications of the mathematical model depends on the assumed modelling goal. For example, the energy rating of the finished engine design can usually be carried out based on the simplest combustion process models. In contrast, designing the shape of the combustion chamber already requires the use of complex models, taking into account the movement of masses in the engine cylinder (CuperPrzybylska, 2018).

The purpose of the work was to prepare a numerical model of a piston engine, four-stroke selfignition engine, with a design similar to that used in shipbuilding. The numerical model is to be used to study air parameters and temperature of exhaust gases at a selected test facility.

The model will be limited to the following elements modelling of: the thermal circulation of the piston engine, the cargo exchange process, the compression process, the injection and combustion process, the construction and analysis of indicator diagrams.

The developed model has been verified by research on a real object in order to compare calculations related to combustion pressure and thermodynamic parameters of air and exhaust gases.

\section{RESEARCH FACILITY}

The implementation of the work objective requires the selection of a research facility. The requirement for the test facility is the possibility of obtaining detailed data related to the geometry of the crank-crank system, the charge exchange system and the fuel system. Therefore, the selected test object is the generating set whose diagram is presented in Fig. 1. The team consists of 3-cylinder piston engine, 4-stroke piston, Al25/30 Sulzer marine engine.

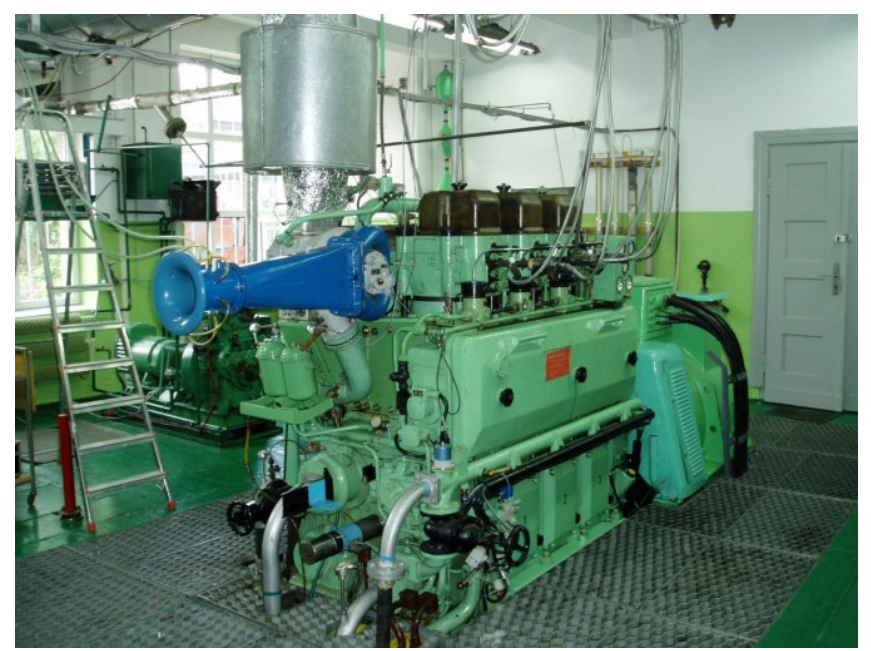

Fig. 1. Photo of the SULZER 3AL25/30 piston engine.

This means, among other things, that the engine cooling system is based on a high and lowtemperature water circuit, with the low-temperature circuit being sea water, in this case the external water system, cooled by two columns of raincoats. The engine is topped up with the VTR 160 Brown-Boveri turbocharger using a shell-and-tube air cooler.

The fuel system is Bosch type injection pumps, controlled by the rotational speed regulator through fuel strips and multi-hole fuel injectors. Fuel injectors are centrally located in the engine cylinder heads.

The AL25/30 engine is coupled with the GD-500-50 generator which transmits the generated electrical energy to the knife resistor. The engine is installed in the Maritime Laboratory of Gdynia Maritime University and works at a constant rotational speed of $750 \mathrm{rpm}$. 
The choice of this position was due to the possibility of obtaining detailed data for the model and widespread use in the shipbuilding industry. The basic parameters of the test facility are presented in Table 1, and the appearance of the position in Figure 1.

Table 1.

AL25/30 engine parameters.

\begin{tabular}{|l|c|c|}
\hline \multicolumn{1}{|c|}{ Parameter } & Unit & Value \\
\hline Rotational speed & $\mathrm{rpm}$ & 750 \\
\hline Cylinder number & - & 3 \\
\hline Cylinder diameter & $\mathrm{mm}$ & 250 \\
\hline Stroke & $\mathrm{mm}$ & 300 \\
\hline Compression ratio & - & 12.7 \\
\hline Fuel nozzle opening pressure & $\mathrm{MPa}$ & 25 \\
\hline Injection timing & ${ }^{\circ}$ before TDC & 18 \\
\hline
\end{tabular}

The measurement system includes the following subsystems measurement of: combustion pressure, fuel injection pressure, fuel consumption exhaust gas composition and measurement of slowly variable pressures and temperatures: air, exhaust gases, cooling water, oil and fuel. During the tests, the engine operated with a $250 \mathrm{~kW}$ load determined on the basis of the electrical output power from a generator mechanically coupled to the engine. The measurement results were recorded in quasi-established conditions. It is recognized that such conditions occur when the temperature of the exhaust gases measured has changed after the turbocharger are not more than $1 \mathrm{C} / \mathrm{min}$. During the measurements, three parallel measurements (three repeats) were carried out.

During the tests, the combustion pressure was registered in all engine cylinders using Kistler 6613CG1 sensors coupled to a voltage amplifier. Each observation involved 7 revolutions of the crankshaft with a sampling rate of 720 measurements per crankshaft rotation. In addition, the fuel pressure before injectors was measured using Kistler 4067E2000DS1-2.0 sensors with digital temperature compensation and with a dedicated Kistler 4624AK11 current amplifier. The slow-changing signals were also recorded, in particular the temperature of the exhaust gases behind individual cylinders and before and after the turbocharger. For this purpose, Pt100 sensors with a measuring range of $0-650^{\circ} \mathrm{C}$ and an accuracy of $\pm 1.35 \%$, coupled to a voltage amplifier and a 16-bit analog-to-digital converter were used.

\section{MODEL ASSUMPTIONS}

The main purpose of the work is to develop a working model of a marine piston engine and its verification based on the actual data of the 3AL25/30 engine.

This goal can be achieved by using a one-dimensional model. This model includes the following partial models:

- combustion process model,

- model of heat exchange in the engine cylinder construction elements,

- model of flows in air and exhaust channels,

- emission model of exhaust gases,

- mechanical friction model,

- model of phenomena occurring in the turbocharger,

- heat exchange model in the radiator.

Functional dependence between individual models is presented in Figure 2.

In the diagram shown $\mathrm{C} 1, \mathrm{C} 2$ and $\mathrm{C} 3$ have been marked with engine cylinders in which the combustion and heat exchange process was modelled. The model also includes mathematical descriptions of cylinder valve timing, piston movement, and direct fuel injection. The cylinders are connected to the pulse exchangers $\mathrm{J} 1$ and $\mathrm{J} 2$ via the flue ducts 17,18 and 19 . The pulse exchangers are in fact exhaust gas channels directed at an angle. The exhaust gases flow through channel 21 and 22 to the T turbine and exit outside via channel 20. 


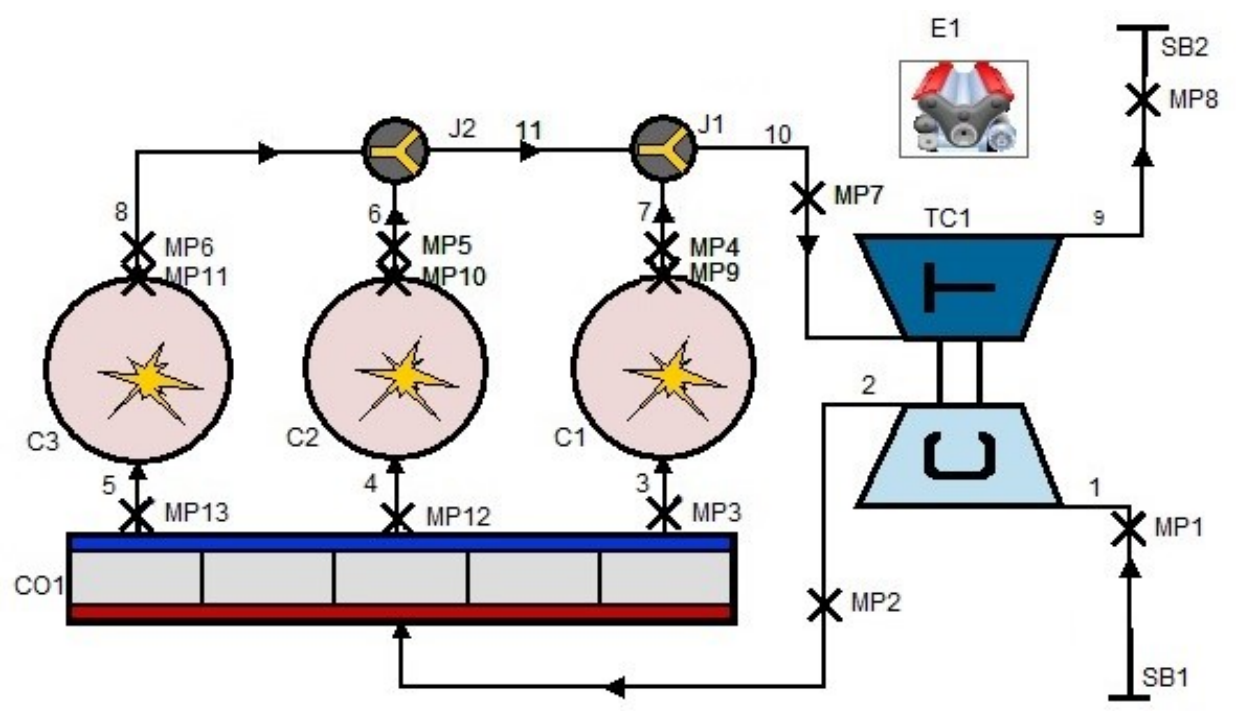

Fig. 2. Model of the research object in the AVL Boost program.

The ambient air parameters are entered into the model at the SB1 and SB2 nodes. The air through the channel 12 is supplied to the compressor $C$, then through the channel 13 to the air cooler CO1. After cooling, the air enters the engine cylinders via channels 14,15 and 16. MP symbols are marked with places for which engine performance parameters have been calculated. The E1 icon allows you to enter the basic engine and model parameters into the model. The most important of them that have been accepted are: rotation speed - $t 750 \mathrm{rpm}$, engine type - 4-stroke in-line, order of ignitions - in cylinders presented in the values of the rotation angle of the cortex shaft, respectively 00,4800 and 2400 , oil temperature - SAE10 equal to $670 \mathrm{C}$.

\section{VALIDATION OF RESULTS}

The model described in Chapter 4 was used to calculate the operating parameters of the test facility under a load of $250 \mathrm{~kW}$. Validation consisted in a comparison of measured and calculated values. The values of slow-changing parameters are presented in Table 2.

Table 2.

Comparison of the values of selected engine work parameters obtained by modelling and measurements.

\begin{tabular}{|l|c|c|c|}
\hline \multicolumn{1}{|c|}{ Parameter } & Model & Measurement & Error [\%] \\
\hline The charge air pressure after the air cooler [MPa] & 0,80 & 0,84 & 4,46 \\
\hline Air pressure before the boost air cooler $[\mathrm{kPa}]$ & 0,82 & 0,85 & 3,88 \\
\hline The charge air temperature after the cooler $\left[{ }^{\circ} \mathrm{C}\right]$ & 34,80 & 31,99 & 8,76 \\
\hline Cylinder temperature $1\left[{ }^{\circ} \mathrm{C}\right]$ & 493,10 & 459,2 & 7,38 \\
\hline Cylinder temperature 2 $\left[{ }^{0} \mathrm{C}\right]$ & 426,70 & 475,2 & 10,21 \\
\hline Cylinder temperature $3\left[{ }^{\circ} \mathrm{C}\right]$ & 440,60 & 401,9 & 9,64 \\
\hline The exhaust gas temperature before the turbine $\left[{ }^{\circ} \mathrm{C}\right]$ & 516,30 & 527,0 & 2,04 \\
\hline The exhaust temperature behind the turbine $\left[{ }^{\circ} \mathrm{C}\right]$ & 337,20 & 405,4 & 16,83 \\
\hline The charge air temperature after the compressor $\left[{ }^{0} \mathrm{C}\right]$ & 106,40 & 110,1 & 3,32 \\
\hline
\end{tabular}

According to the presented data, the majority of parameter values obtained by modelling do not deviate from the measured values by more than $11 \%$, only the exhaust gas pressure behind the turbocharger is $81 \%$ greater than the measured value. It should be noted, however, that the exhaust pressure values in this place are very small in the order of a few kilopascals. In addition, the outlet channel was modelled as a straight pipeline and in the research facility it is a complex construction, consisting of several pipelines, a silencer and a system for throttling the flow. Such a complex construction causes a considerable pressure drop.

Figure 3 presents the results of the validation of the combustion pressure in the cylinder 3 of the test facility. The orange colour was determined by the pressure measured on the indicator cock, while the blue colour was determined by the combustion pressure values obtained by 
modelling. The obtained modelling results are qualitatively convergent with the results obtained through measurements. This means that the Vibe model coefficients were selected correctly, and the burning time was also correctly estimated.

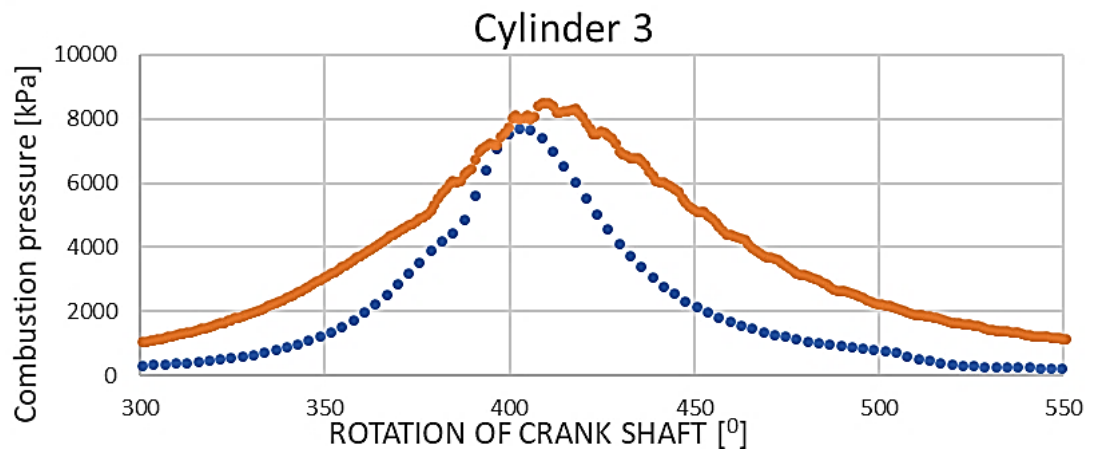

Fig. 3. Comparison of the combustion pressure in cylinder 3 values measured on the real object and obtained by modeling (orange line: measure, blue line: calculation).

It can be noticed that on all cylinders of the test object the maximum combustion pressure obtained by measurements is higher than the pressure obtained by modelling by $6.3 \%, 7.6 \%$ and $6.3 \%$ respectively. This is probably due to the introduction of too high values of heat transfer coefficients in the Woshnia model. Modelling with the presented parameters causes heat losses in each cylinder by an average of $3.9 \%$ to the piston crown, $4.1 \%$ to the cylinder head and $5.9 \%$ to the cylinder liner, which gives over $13 \%$ of the heat loss. Decreasing the value of the mentioned factors causes the increase of pressure values, however, the effect of this is an increase in the temperature of the exhaust gases behind the cylinders. It should be noted that the location of the maximum measured combustion pressure is delayed in relation to the model values by an average of $800 \mathrm{WK}$. This is the expected effect, because the measurement of the combustion pressure takes place at the indicator cock. A similar result was obtained in the work (Pawletko et all, 2010).

\section{ANALYSIS OF MODELLING RESULTS}

A positively valid model of a research object was used to analyse the phenomena occurring in its functional systems. The air flow characteristics are qualitatively close to each other, but shifted in phase in accordance with the valve timing. The calculation results show that the largest averaged air flow is through cylinder 2 and is $165.6 \mathrm{~g} / \mathrm{s}$, to cylinder 1 the average air mass stream is $160.9 \mathrm{~g} / \mathrm{s}$, and to cylinder 3 only $147.2 \mathrm{~g} / \mathrm{s}$. It can be observed that after about $120^{\circ} \mathrm{C}$ a momentary air flow occurs in the opposite direction, i.e. from the cylinder to the inlet channel. This is the operating period of the test facility in which the exhaust valve is opened, i.e. the period of covering (co-loading) of inlet and exhaust valves. This is an unfavourable phenomenon and can be avoided by delaying the opening of the exhalation valve.

However, it should be realized that the presented characteristics may not be reflected in the work of the real object, because the model does not use real values of flow resistance coefficients by valves. At the end of the intake valve opening phase, another negative air flow can be observed, i.e. flow towards the intake duct. This is most likely caused by closing the valve plug and by pumping air above the plug towards the inlet channel.

According to the presented modelling results in the exhaust manifold there is a pressure pulsation in the three maximum values corresponding to the exhalation from the three cylinders of the test object. The largest central value of $0.454 \mathrm{MPa}$ comes from 1 cylinder, located closest to the turbine. The first from the left, the maximum value comes from the exhaust of the cylinder 2 and amounts to $0.417 \mathrm{MPa}$. The last smallest value comes from the exhaust from the cylinder furthest away from the turbine and amounts to $0.335 \mathrm{MPa}$. Modelling results show that the cylinder distance from the turbocharger in the case of pulse charging has a significant impact on the amount of energy supplied to the turbine with exhaust gases. Figure 4 presents the compressor and turbine power characteristics obtained by modelling. 


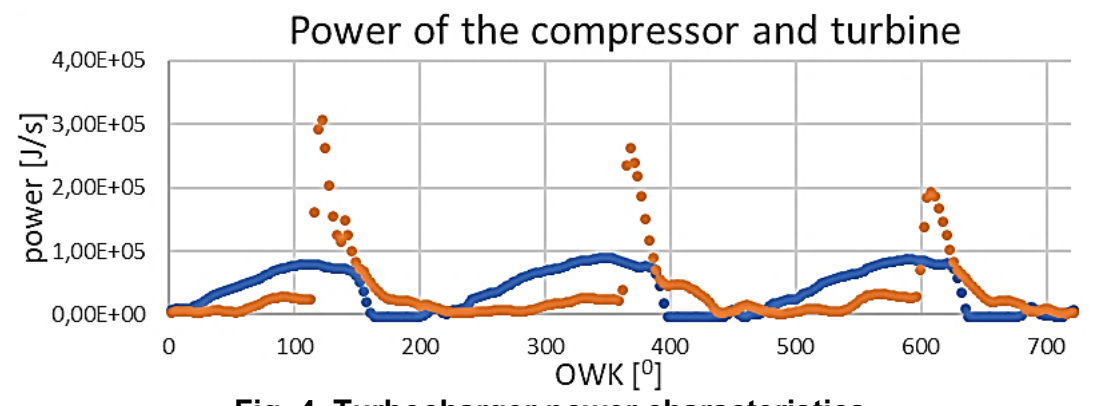

Fig. 4. Turbocharger power characteristics (orange line: turbine, blue line: compressor).

\section{CONCLUSION}

The purpose of the work was to prepare a numerical model of piston engine, four-stroke selfignition engine, with a design similar to that used in shipbuilding. This model was used to study air parameters and exhaust gas temperature at a selected test facility. Therefore, the selected test facility is a Sulzer 3-cylinder, 4-stroke piston engine Al25/30 in marine version. The model of the selected research object was made in the AVL Boost program.

The assumed goal of the work has been achieved. Validation was performed to check the operation of the model. Most parameter values obtained by modelling do not deviate from the measured values by more than $12 \%$, only the calculated exhaust gas pressure downstream of the turbocharger is $81 \%$ greater than the measured value.

The error between modelled and measured values is sufficient for simple engineering analyses. Thanks to this, the developed model can be used for calculations and tests without the need for costly measurements on a real object. This model can also be developed with the equations of chemical kinetics of combustion processes, and thus can be used to analyse the composition of exhaust gases.

Calculations using the model created in the work allow for the analysis of phenomena taking place in the research facility, in particular:

- it can be seen that on all cylinders of the test object the maximum combustion pressure obtained by measurements is higher than the pressure obtained by modelling by $6.3 \%$, $7.6 \%$ and $6.3 \%$ respectively. This is probably due to the introduction of too high values of heat transfer coefficients in the Woshnia model. Modelling with the presented parameters causes heat losses in each cylinder by an average of $3.9 \%$ to the piston crown, $4.1 \%$ to the cylinder head and $5.9 \%$ to the cylinder liner, which gives over $13 \%$ of the heat loss.

- at the end of the opening of the exhalation valves, the flow rate increases from approximately $0.4 \mathrm{~kg} / \mathrm{s}$ to $1.1 \mathrm{~kg} / \mathrm{s}$, which is caused by closing the intake valves. Valve wrapping causes so-called exhaust gas recirculation, which in the case of a research facility is around $13.3 \%$,

- the power of the turbine is not constant during the operating cycle of the test facility and changes with the pressure changes in the exhaust duct ahead of the turbocharger. These changes are significant and amount to even $300 \mathrm{~kJ} / \mathrm{s}$ with a minimum instantaneous power of $10-15 \mathrm{~kJ} / \mathrm{s}$. The average turbine operation in accordance with the model calculations is $6.81 \mathrm{~kJ}$,

- the turbine drives a supercharging compressor whose calculated average operation is 6.52 $\mathrm{kJ}$. The operation of the turbocharger is related to energy losses, therefore the compressor power changes do not exceed $100 \mathrm{~kJ} / \mathrm{s}$,

- the largest amount of air is supplied to cylinder 3 and, according to calculations, is 172.8 $\mathrm{g} / \mathrm{s}$. Air is supplied to the cylinder 2 in the amount of $166.8 \mathrm{~g} / \mathrm{s}$, while for the cylinder 1 only $160.4 \mathrm{~g} / \mathrm{s}$,

\section{ACKNOWLEDGMENTS}

The project was supported by AVL Company according to University Partnership Program and license of AVL Fire software. 


\section{REFERENCES}

AVL BOOST :Version 2013.2 (2009) Therory documentacion. AVL List Gmbh,

Bader P., McLaren D, Quispel G.R.W., WebbM.(2016) Volume preservation by

Cuper-Przybylska D. (2018). Analiza modeli procesów spalania w cylindrze silnika łłokowego. Autobusy - Technika, Eksploatacja, Systemy Transportowe, [S.I.], v. 218, n. 4, pp. 48-52

Cuper-Przybylska D. (2016). Analysis of the possibilities of using modern process working marine diesel engine. Journal of KONES Powertrain and Transport, Vol. 23, No. 2 pp 8188

Dowell P.G., Akehurst S., Burke R.D. (2017). A real-time capable mixing controlled combustion model for highly diluted conditions. In Energy, Volume 133.

Guardiola C., Olmeda P., Pla B., Bares P. (2017) In-cylinder pressure based model for exhaust temperature estimation in internal combustion engines, In Applied Thermal Engineering, Volume 115.

Jeongwoo L. J., Sanghyun C., Kyoungdoug M., Minjae K., Hyunsung J., Hyounghyoun K., Yohan C. (2017). Classification of diesel and gasoline dual-fuel combustion modes by the analysis of heat release rate shapes in a compression ignition engine, In Fuel, Volume 209 ,

Kowalski J. (2014) An experimental study of emission and combustion characteristics of marine diesel engine with fuel pump malfunctions, Applied Thermal Engineering, Volume 65, Issues 1-2, pp. 469-476.

Lyubarskyy P. and BartelD. (2016). 2D CFD-model of the piston assembly in a diesel engine for the analysis of piston ring dynamics, mass transport and friction, Tribology International, Volume 104, pp. 352-368,

Magnussen, B. F. and Hjertager, B.H. (1977). On mathematical modeling of turbulent combustion with special emphasis on soot formation and combustion. Sixteenth International Symposium on Combustion, Pittsburgh: The Combustion Institute.

Pawletko R. and Polanowski S. (2012). Influence of gas channels of medium speed marine engines on the accuracy of determination of diagnostic parameters based on the indicator diagrams, Journal of Polish CIMAC. 7-2: pp. 139-146.

Pawletko, R. and Polanowski, S. (2010). Research of the influence of Marine diesel engine Sulzer AL. 25/30 load on TDC position on the indication graph, Journal of KONES, Vol. 17 , No. 3.

Rakopoulos C.D., Antonopoulos K.A., Rakopoulos D.C.(2006). Multi-zone modeling of Diesel engine fuel spray development with vegetable oil, bio-diesel or Diesel Fuels. Energy Conversion and Management 47, pp. 1550-1573.

Saeed K., (2017). A novel regenerative multiple zones model for modelling the premixed charge stirred chemical reactor based combustion engines. In Journal of the Energy Institute, Volume 90, Issue 5.

Trindade W. and Santos R. (2018). 1D modeling of SI engine using n-butanol as fuel: Adjust of fuel properties and comparison between measurements and simulation. Energy Conversion and Management, Volume 157, pp. 224-238

Zhang, Q., Hao, Z., Zheng, X., Yang, W. (2017) Characteristics and effect factors of pressure oscillation in multi-injection DI diesel engine at high-load conditions. Applied Energy, 195, pp. 52-66. 